\title{
Development of an Efficient Plant Regeneration System for the Selenium-hyperaccumulator Astragalus racemosus and the Nonaccumulator Astragalus canadensis
}

\author{
Chiu-Yueh Hung and Jiahua Xie ${ }^{1}$ \\ Department of Pharmaceutical Sciences, Biomanufacturing Research \\ Institute \& Technology Enterprise, North Carolina Central University, \\ 1801 Fayetteville Street, Durham, NC 27707
}

Additional index words. 'Cream Milkvetch', 'Canadian Milkvetch', organogenesis, callus, multiple shoots

\begin{abstract}
A method of in vitro plant regeneration for both the selenium-hyperaccumulator Astragalus racemosus 'Cream Milkvetch' and the nonaccumulator Astragalus canadensis 'Canadian Milkvetch' was developed with two induction media, M1 and M2. The M1 and M2 contain Murashige and Skoog basal medium plus vitamins, $8.07 \mu \mathrm{M} N$-(2-chloro-4pyridyl)- $N^{\prime}$-phenylurea, $2.5 \%\left(\mathrm{w} \cdot \mathrm{v}^{-1}\right)$ sucrose, $0.7 \%\left(\mathrm{w} \cdot \mathrm{v}^{-1}\right)$ agar $(\mathrm{pH} 5.7)$, and $0.89 \mu \mathrm{M}$ or $3.12 \mu \mathrm{M}$ a-naphthaleneacetic acid, respectively. In vitro cultures were initiated on these two types of media with three types of explants: cotyledons, hypocotyls, and roots. More than $\mathbf{9 3 \%}$ of cultured explants from both species could form calli or calli with shoots. With regard to shoot formation, $A$. canadensis could produce multiple shoots from all types of explants more efficiently than $A$. racemosus. The highest shoot induction was approximately three shoots per explant in $A$. racemosus, whereas $A$. canadensis could reach $\approx 10$ shoots per explant. M1 could induce more shoots than M2 no matter what type of explant was used, but the overall induction rates were no significant difference. Among the three types of explants used, the cotyledons were the best explants for shoot induction in $A$. canadensis, whereas hypocotyls were the best in $A$. racemosus. In $A$. racemosus, shoots could also be obtained from calli on the rooting medium containing Murashige and Skoog basal plus vitamins, $2.84 \mu \mathrm{M}$ indole-3 acetic acid, $2.5 \%\left(\mathrm{w} \cdot \mathrm{v}^{-1}\right)$ sucrose, and $0.7 \%\left(\mathrm{w} \cdot \mathrm{v}^{-1}\right)$ agar (pH 5.7). Approximately $43 \%$ of $A$. canadensis shoots and $19 \%$ of $A$. racemosus shoots could be rooted on the rooting medium.
\end{abstract}

Selenium (Se) is an essential micronutrient for animals, including humans (Birringer et al., 2002), although for a long time, it was only known for its toxicity (Schwarz and Foltz, 1957). Recent studies have shown that Se-enriched plants are wanted for both cancer prevention (Finley, 2005) and Se phytoremediation (Berken et al., 2002; Sors et al., 2005). In nature, several Se-hyperaccumulating species of the genus Astragalus originating from seleniferous soils have been characterized (Trelease and Trelease, 1939). They cannot only tolerate high Se in soil, but can also hyperaccumulate Se at concentrations of up to 20 to 40 mg per gram of dry matter in their shoots when they grow under 2 to $10 \mathrm{ppm} \mathrm{Se}$ in

\footnotetext{
Received for publication 12 Aug. 2008. Accepted for publication 16 Sept. 2008.

This work was supported by a Biotechnology Research Grant (2007-BRG-1223) from the North Carolina Biotechnology Center and a startup fund from the Golden LEAF Foundation to the Biomanufacturing Research Institute \& Technology Enterprise (BRITE).

${ }^{1}$ To whom reprint requests should be addressed; e-mail jxie@nccu.edu
}

natural soils (Davis, 1972). However, these Se accumulators are not edible plants for chemopreventive purposes and have very limited applications for Se phytoremediation because of their extremely slow growth and low biomass (Cunningham et al., 1997). In addition, the Se-hyperaccumulating plants cannot cross with any food plants as a result of genetic distance. Molecular cloning and genetic engineering may offer a better way to isolate genes related to the Se-hyperaccumulating property that could be transferred to other crop plants to create Se-enriched transgenic plants.

Currently, the functional analysis of the Astragalus genes related to Se accumulation is limited because there is no transformation and regeneration system available for the Astragalus species. So far, only one Seaccumulating gene, encoding selenocysteine methyltransferase, has been isolated from a Se hyperaccumulator, Astragalus bisulcatus (Neuhierl et al., 1999). Other genes that are also responsible for $\mathrm{Se}$ accumulation might exist. The discovery and study of additional Se-accumulating genes will help us to understand the mechanism of Se accumulation in Se hyperaccumulators and ultimately to develop transgenic plants with the
Se-hyperaccumulating capacity. Gene transformation, however, needs reliable regeneration systems.

A previous report showed that calli could be induced from the hypocotyls of five Sehyperaccumulator and three nonaccumulator species of Astragalus by including $13.57 \mu \mathrm{M}$ 2,4-dichlorophenoxyacetic acid (2,4-D) in the induction medium (Ziebur and Shrift, 1971). Both the A. racemosus and A. canadensis species used in the present study were in their report. When those calli were subcultured, they failed to regenerate plants despite that incompletely developed roots and shoots were observed in some of their early subcultures, although they had been subcultured and maintained for several years (Ziebur and Shrift, 1971). Synthetic auxin, $2,4-\mathrm{D}$, is a strong hormone that is widely used to induce callus formation (Khanna and Raina, 1998). However, the concentration of $13.57 \mu \mathrm{M}$ is considerably high for plant tissue culture, in which calli derived from an induction medium with such a high concentration of 2,4-D generally lose further dedifferentiation ability (Xie et al., 1995).

The objective of the current study was to establish a plant regeneration system for both the Se-hyperaccumulator $A$. racemosus and the nonaccumulator $A$. canadensis. To induce shoots, another more moderate auxin, a-naphthalene acetic acid (NAA), was chosen to combine with cytokinin 6-benzylaminopurine (BA) and cytokine-like $N$-(2-chloro-4pyridyl)- $N$-phenylurea (CPPU). CPPU has been proven to be able to effectively improve the efficiency of shoot formation and somatic embryogenesis in different plant species (Fiore et al., 2002; Millan-Mendoza, 1998; Murthy and Saxena, 1994; Nakajima et al., 2000; Tsuro et al., 1999; Zhang et al., 2005). We report our newly established plant regeneration system for $A$. racemosus and $A$. canadensis. Current results demonstrate that CPPU combined with NAA was good for A. racemosus and A. canadensis tissue cultures. Culture efficiencies of two species and three types of explants are compared.

\section{Materials and Methods}

Seedling preparation. Seeds of the Sehyperaccumulator $A$. racemosus and the nonaccumulator $A$. canadensis were purchased from the Prairie Moon Nursery (Winona, $\mathrm{MN})$. They were scarified by silica sand and cold-pretreated at $4{ }^{\circ} \mathrm{C}$ for 2 months before germination. Approximately 300 seeds of each species were germinated for experiments. Seeds were first surface-sterilized with $70 \%$ ethanol for $1 \mathrm{~min}$ and then rinsed with sterile water twice. They were then sterilized in a $40 \%$ Clorox (Clorox Professional Products Company, Oakland, CA; a commercial bleach containing $6 \%$ of the a.i., $\mathrm{NaOCl}$ ) solution with $1 \%$ Tween 20 for 20 $\mathrm{min}$ and rinsed with sterile distilled water five times. Finally, sterilized seeds were germinated on Murashige and Skoog (MS) basal medium with vitamins (ID: M519; Phyto Technology Laboratories, Lenexa, KS) 
(Murashige and Skoog, 1962), 2.5\% (w· $\left.\mathrm{v}^{-1}\right)$ sucrose, and $0.7 \%\left(\mathrm{w} \cdot \mathrm{v}^{-1}\right)$ agar (Acros Organics, Morris Plains, NJ). The $\mathrm{pH}$ was adjusted to 5.7 before autoclaving. Each $100 \times 15-\mathrm{mm}$ sterile petri dish (Fisher Scientific, Inc., Pittsburgh, PA) containing $20 \mathrm{~mL}$ of MS solid medium was placed with eight seeds. Petri dishes were then sealed with parafilm M (Fisher Scientific, Inc.) and incubated in a growth chamber under a condition of 16-h light and 8-h dark cycle at $25^{\circ} \mathrm{C}$ with a light intensity of $50 \mu \mathrm{mol} \cdot \mathrm{m}^{-2} \cdot \mathrm{s}^{-1}$. After 4 to $7 \mathrm{~d}$, most vital seeds started to germinate.

Explant preparation. In a preliminary test, all cotyledons were harvested from 7-d-old seedlings. In a formal experiment, cotyledons, hypocotyls, and roots of 3-week-old seedlings were separated for tissue culture. Roots and hypocotyls were cut into $\approx 0.6$ - to $0.8-\mathrm{cm}$ long segments and cotyledons were cut into a $0.4-$ to $0.5-\mathrm{cm}^{2}$ area for culture. Because the cotyledons of these two species were small, almost all or the middle part of the cotyledon was needed for one piece of explant.

Preliminary culture test. Three pretesting experiments were conducted for callus and shoot inductions with the media containing an identical MS basal plus vitamins (Phyto Technology Laboratories), $2.5 \% \quad\left(\mathrm{w} \cdot \mathrm{v}^{-1}\right)$ sucrose, and $0.7 \%\left(\mathrm{w} \cdot \mathrm{v}^{-1}\right)$ agar $(\mathrm{pH} 5.7)$ but different combinations of growth regulators. Five to 10 pieces of cotyledon explants were used to test each condition. Five explants were transferred onto a $100 \times 15$-mm sterile petri dish containing $20 \mathrm{~mL}$ of medium. The first pretesting experiment was a preliminary test with $8.07 \mu \mathrm{M}$ CPPU and different concentrations of NAA. The induction medium containing $0.89 \mu \mathrm{M}$ NAA and $8.07 \mu \mathrm{M}$ CPPU was adapted from the medium used by Zhang et al. (2005) for Golden Pothos tissue culture. Three additional hormone combinations, 0 , 3.12, and $5.35 \mu \mathrm{M}$ NAA, were included with $8.07 \mu \mathrm{M}$ CPPU. The second pretesting experiment was the test of $0,4.52$, or $13.57 \mu \mathrm{M}$ of 2,4-D combined with $13.94 \mu \mathrm{M}$ kinetin. In this pretest, we intended to repeat the method developed by Ziebur and Shrift (1971) using a lower concentration of 2,4-D. The third pretesting experiment was the test of $4.49 \mu \mathrm{M} \mathrm{BA}$ combined with $0,0.89,3.12$, or $5.35 \mu \mathrm{M}$ NAA.

Induction media, explants, and experimental design in the formal experiment. Based on the pretesting results, two best induction media with $0.89 \mu \mathrm{M}$ NAA $+8.07 \mu \mathrm{M}$ CPPU (named M1) and $3.12 \mu \mathrm{M}$ NAA $+8.07 \mu \mathrm{M}$ CPPU (named M2) were selected to evaluate tissue culture efficiencies for $A$. racemosus and A. canadensis with three different types of explants: cotyledons, hypocotyls, and roots. Every eight explants were cultured onto a 100 $\times 15$-mm sterile petri dish containing $20 \mathrm{~mL}$ of medium. Each petri dish was counted as a replicate. A total of nine petri dishes (representing nine replicates) were used for each treatment. All petri dishes were sealed with parafilm $\mathrm{M}$ and incubated in a growth chamber under a 16-h light and 8-h dark cycle at $25^{\circ} \mathrm{C}$ with a light intensity of $50 \mu \mathrm{mol} \cdot \mathrm{m}^{-2} \cdot \mathrm{s}^{-1}$. After 5 weeks of initial culture, all explants with induced calli, shoots, or both were transferred onto fresh medium for another 3 weeks to induce more shoots and to maintain the growth of shoots.

Data collection and analysis. Numbers of calli and shoots from each plate were counted after 8 weeks of culture. An average of 72 explants from a total of nine petri dishes for each treatment was taken for statistical analysis. Data for the percentage of explants with calli and shoots, or callus only, and the number of shoots produced per explants were subjected to statistical analysis. The variances among the 12 treatments were analyzed by the JMP software (SAS Institute, Cary, NC), and their means separation was performed using least significant means difference Student's $t$ test at $P \leq 0.05$.

Rooting. After recording callusing and shooting rates, a total of 108 shoots from A. canadensis cotyledon culture and 94 shoots from $A$. racemosus cotyledon culture with more than two small true leaves and a length greater than $1 \mathrm{~cm}$ were isolated individually for rooting. The rooting medium was MS basal plus vitamins, $2.84 \mu \mathrm{M}$ indole- 3 acetic acid (IAA), $2.5 \%\left(\mathrm{w} \cdot \mathrm{v}^{-1}\right)$ sucrose, and $0.7 \%$ $\left(\mathrm{w} \cdot \mathrm{v}^{-1}\right)$ agar $(\mathrm{pH} 5.7)$. Five to six shoots were transplanted in a $100 \times 20-\mathrm{mm}$ sterile petri dish (Fisher Scientific, Inc.) containing 25 $\mathrm{mL}$ of rooting medium. All petri dishes were sealed with parafilm $M$ and incubated in a growth chamber under a 16-h light and 8-h dark cycle at $25^{\circ} \mathrm{C}$ with a light intensity of $50 \mu \mathrm{mol} \cdot \mathrm{m}^{-2} \cdot \mathrm{s}^{-1}$. Every 4 weeks, shoots were transferred to a fresh rooting medium for a total of an 8-week period. Some calli derived from $A$. racemosus cotyledon cultures were also transferred to rooting medium for shoot induction and rooting test.

\section{Results}

Preliminary culture test. To establish a plant regeneration system for the Se-hyperaccumulator $A$. racemosus and the nonaccumulator $A$. canadensis, we first pretested the induction media with 11 different growth regulator combinations using five to 10

Table 1. The number of cotyledon explants from $A$. canadensis and A. racemosus forming calli or calli with shoots on different pretesting media. ${ }^{\mathrm{z}}$

\begin{tabular}{|c|c|c|c|c|c|c|}
\hline Species & & inadens & & & acemosu & \\
\hline Growth regulators ${ }^{y}$ & $\begin{array}{c}\text { Total } \\
\text { explants } \\
\text { tested }\end{array}$ & $\begin{array}{c}\text { Calli } \\
\text { with } \\
\text { shoots }\end{array}$ & $\begin{array}{l}\text { Calli } \\
\text { only }\end{array}$ & $\begin{array}{c}\text { Total } \\
\text { explants } \\
\text { tested }\end{array}$ & $\begin{array}{c}\text { Calli } \\
\text { with } \\
\text { shoots }\end{array}$ & $\begin{array}{l}\text { Calli } \\
\text { only }\end{array}$ \\
\hline $8.07 \mu \mathrm{M} \mathrm{CPPU}$ & 5 & 2 & 1 & 5 & 1 & 2 \\
\hline $8.07 \mu \mathrm{M}$ CPPU $+0.89 \mu \mathrm{M}$ NAA & 5 & 4 & 0 & 5 & 2 & 3 \\
\hline $8.07 \mu \mathrm{M}$ CPPU $+3.12 \mu \mathrm{M}$ NAA & 5 & 5 & 0 & 5 & 3 & 2 \\
\hline $8.07 \mu \mathrm{M}$ CPPU $+5.35 \mu \mathrm{M}$ NAA & 5 & 3 & 1 & 5 & 1 & 2 \\
\hline $13.94 \mu \mathrm{M}$ kinetin & 10 & 0 & 0 & 10 & 0 & 0 \\
\hline $13.94 \mu \mathrm{M}$ kinetin $+4.52 \mu_{\mathrm{M}} 2,4-\mathrm{D}$ & 10 & 0 & 5 & 10 & 0 & 5 \\
\hline $13.94 \mu \mathrm{M}$ kinetin $+13.57 \mu \mathrm{M} 2,4-\mathrm{D}$ & 10 & 0 & 6 & 10 & 0 & 5 \\
\hline $4.49 \mu \mathrm{M} \mathrm{BA}$ & 5 & 1 & 1 & 5 & 0 & 1 \\
\hline $4.49 \mu \mathrm{M} \mathrm{BA}+0.89 \mu \mathrm{M}$ NAA & 5 & 1 & 1 & 5 & 0 & 1 \\
\hline $4.49 \mu \mathrm{M} \mathrm{BA}+3.12 \mu \mathrm{M}$ NAA & 5 & 2 & 1 & 5 & 1 & 0 \\
\hline $4.49 \mu \mathrm{M} \mathrm{BA}+5.35 \mu \mathrm{M}$ NAA & 5 & 1 & 2 & 5 & 1 & 1 \\
\hline
\end{tabular}

${ }^{\mathrm{z}}$ Each petri dish contained five cotyledon explants. Each treatment has either one or two petri dishes. ${ }^{\mathrm{y}}$ The basic medium contained Murashige and Skoog mineral salts plus vitamins, $2.5 \%\left(\mathrm{w} \cdot \mathrm{v}^{-1}\right)$ sucrose, and $0.7 \%\left(\mathrm{w} \cdot \mathrm{v}^{-1}\right)$ agar $(\mathrm{pH} 5.7)$. The growth condition was under a $16-\mathrm{h}$ light and 8 -h dark cycle at $25^{\circ} \mathrm{C}$ with a light intensity of $50 \mu \mathrm{mol} \cdot \mathrm{m}^{-2} \cdot \mathrm{s}^{-1}$.

CPPU = cytokine-like $N$-(2-chloro-4-pyridyl)- $N^{\prime}$-phenylurea; NAA = a-naphthalene acetic acid; 2,4-D = 2,4-dichlorophenoxyacetic acid; $\mathrm{BA}=6$-benzylaminopurine. pieces of cotyledon explants per condition. induction media with $0.89 \mu \mathrm{M}$ NAA +8.07 M CPPU (named M1) and $3.12 \mu \mathrm{M}$ NAA + ( adapted from the medium used by Zhang et al. (2005) for Golden Pothos tissue culture that was shown to be very efficient in terms of the percentages of explants with calli and shoots and the numbers of induced shoots per explant. After culturing for 8 weeks, all racemosus produced calli with shoots on these two media. The M2 seemed to perform even better than the M1. Remaining growth to indurer calli with shoots or could only produce calli. Based on this preliminary test, both M1 and M2 media were selected to develop plant regeneration systems and study their culture responses for $A$. racemosus and canadensis.

Callus and shoot induction with $\mathrm{A}$. canadensis and A. racemosus. Although the cotyledons are considered as the best plants for tissue culture in most species explants may have various culture responses in different species (Komai et al., 1996). To establish an efficient culture system, three different types of explants from each species: with the induction mis, and roots were tested culturing for 4 to $6 \mathrm{~d}$, our first observation was that most explant tissues from $A$. racemosus and A. canadensis were expanded on cotyled and 12 media. Calli appeared on culture in both species (Fig. 1A-B). Some green shoots together with calli were observed in A. canadensis cotyledon explants in the third week, and more green shoots emerged after an additional 2 to 3 weeks of culture (Fig. 1A, E), whereas shoots were first observed after 5 to 6 weeks in A. racemosus cotyledon culture (Fig. 1F). These results Preliminary testing results showed that both cotyledon explants from $A$. canadensis and 

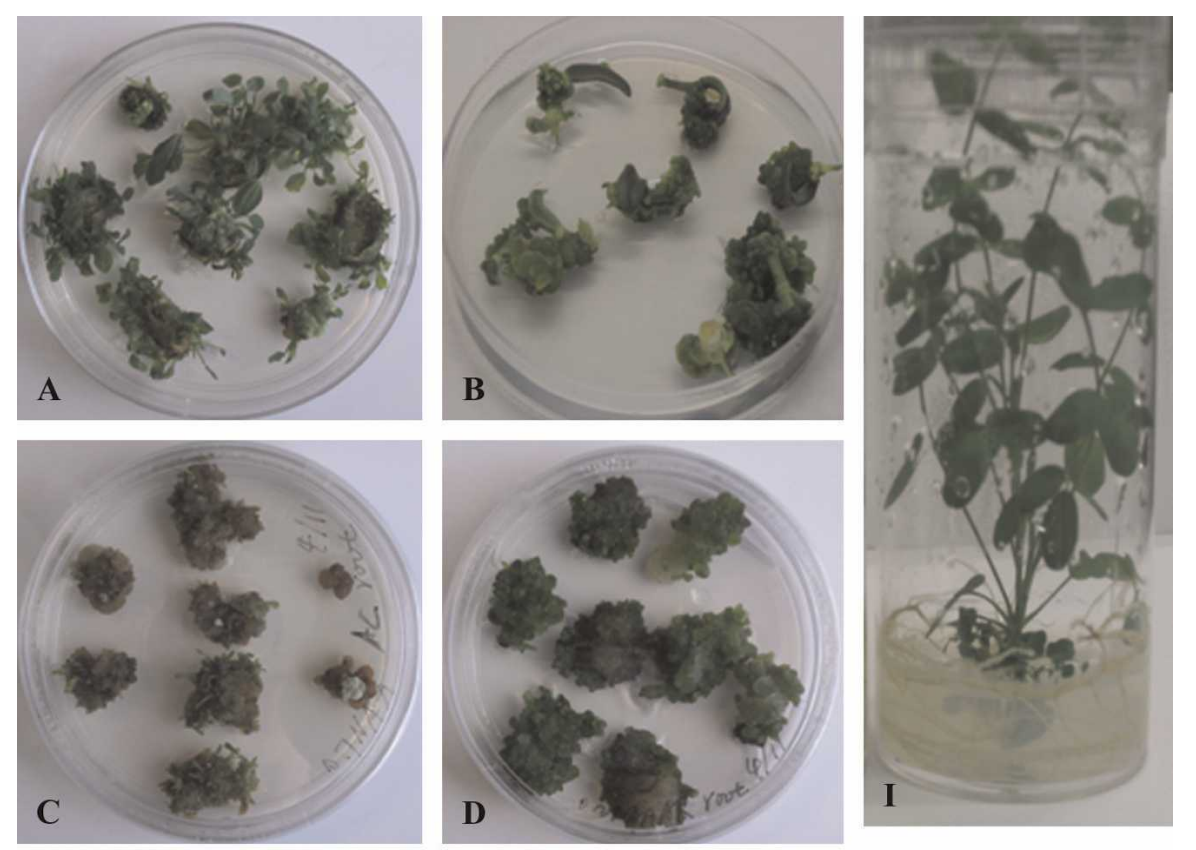

in all treatments. For different species, $\approx 68.1 \%$ to $100 \%$ of explants from $A$. canadensis could produce calli with shoots, whereas those of $A$. racemosus were less capable with only $\approx 12.5 \%$ to $70.8 \%$ producing calli with shoots. However, the remaining $27.8 \%$ to $83.3 \%$ explants of $A$. racemosus could produce calli without shoots.

Compared with the different explants, the percentage of the calli formed with shoots was similar among the three types of explants in $A$. canadensis. They all had a high calluswith-shoot induction rate $(90.3 \%$ to $100 \%)$ except the root explants in M2 medium, in which the rate was $68.1 \%$. In $A$. racemosus, explants from hypocotyls had the best ability to produce calli with shoots $(70.8 \%$ in $\mathrm{M} 1$ and $54.2 \%$ in $\mathrm{M} 2$ ) followed by cotyledons (45.8\% in M1 and 37.5\% in M2) and roots (23.6\% in M1 and $12.5 \%$ in M2).

The number of induced shoots. The induced shoots were compared after 8 weeks of culture. A. canadensis had a greater ability to produce shoots than $A$. racemosus in all three types of explants on the two induction media (Table 3). Each explant from $A$. canadensis cotyledon could produce 10 shoots, whereas explants from $A$. racemosus produced fewer than three shoots. These results further suggest that $A$. canadensis is better equipped than $A$. racemosus to be able to produce shoots under the current culture conditions. For shoot induction, M1 induced more shoots than M2 no matter what type of explant was used, but the overall induction rates were not very different. Moreover, the three types of explants had different abilities to produce shoots. In $A$. canadensis, cotyledons were the best explants for shoot induction with nine to 10 shoots per explant, whereas hypocotyls and roots were equally low in shoot induction. However, for $A$. racemosus, hypocotyls were the best explants for shoot induction with approximately two to three shoots per explant followed by cotyledons and roots.

Shoots from A. racemosus calli. Although many calli of $A$. racemosus did not have any shoot emerge (Fig. 1G), we still transferred some of them onto rooting medium for shoot induction and rooting tests. Surprisingly, after subculture on rooting medium for $\approx 8$ weeks, some calli began to have shoots with leaves and roots as well (Fig. 1H). This result indicated that some $A$. racemosus calli could be used to induce shoots in rooting medium.

Rooting. To examine rooting efficiency, individual shoots longer than $1 \mathrm{~cm}$ were isolated from the cluster of shoots and were put on a rooting medium that consisted of MS basal plus $2.84 \mu \mathrm{M}$ IAA. We isolated 108 shoots from $A$. canadensis cotyledon culture and 94 shoots from $A$. racemosus cotyledon culture for the rooting test. The results showed that only a few shoots could produce roots during the initial 4 weeks of culture on the rooting medium. After they were subcultured on new rooting medium for another 4 weeks, 49 shoots of $A$. canadensis and 18 shoots of $A$. racemosus could be from rust-colored calli were normal and
However, the regenerated shoots derived green (Fig. 1C). Most calli were firm and could produce shoots, whereas a small in the later culture in both species.

Callus and shoot induction rates. The culture results showed that both induction media were good for $A$. canadensis and $A$. racemosus tissue culture, and $93 \%$ to $100 \%$ of placed explants from both species and the three types of explants could produce either calli or calli with shoots after 8 weeks of culture (Table 2). A higher percentage of explants having calli with shoots was obtained in M1 medium than in M2 medium 
Table 2. The percentage of explants from A. canadensis and A. racemosus forming calli or calli with shoots on two induction media. ${ }^{2}$

\begin{tabular}{|c|c|c|c|c|c|}
\hline Species & Medium $^{y}$ & Explants & $\begin{array}{l}\text { Calli with } \\
\text { shoots (\%) }\end{array}$ & $\begin{array}{c}\text { Calli only } \\
(\%)\end{array}$ & $\begin{array}{l}\text { Total culture } \\
\text { response (\%) }\end{array}$ \\
\hline \multirow[t]{6}{*}{ A. canadensis } & M1 & Cotyledons & $98.6 \pm 4.2 \mathrm{a}^{\mathrm{x}}$ & $1.4 \pm 4.2 \mathrm{f}$ & 100 \\
\hline & M1 & Hypocotyls & $98.6 \pm 4.2 \mathrm{a}$ & 0 & 98.6 \\
\hline & M1 & Roots & $100 \pm 0 \mathrm{a}$ & 0 & 100 \\
\hline & M2 & Cotyledons & $95.8 \pm 8.8 \mathrm{a}$ & $4.2 \pm 8.8 \mathrm{f}$ & 100 \\
\hline & M2 & Hypocotyls & $90.3 \pm 13.7 \mathrm{a}$ & $9.7 \pm 13.7 \mathrm{f}$ & 100 \\
\hline & M2 & Roots & $68.1 \pm 14.1 \mathrm{~b}$ & $30.6 \pm 14.1 \mathrm{de}$ & 100 \\
\hline \multirow[t]{6}{*}{ A. racemosus } & M1 & Cotyledons & $45.8 \pm 33.7 \mathrm{c}$ & $47.2 \pm 26.4 \mathrm{~cd}$ & 93.0 \\
\hline & M1 & Hypocotyls & $70.8 \pm 25.8 b$ & $27.8 \pm 24.0 \mathrm{e}$ & 98.6 \\
\hline & M1 & Roots & $23.6 \pm 22.9 \mathrm{de}$ & $76.4 \pm 22.9 \mathrm{ab}$ & 100 \\
\hline & M2 & Cotyledons & $37.5 \pm 25.8 \mathrm{~cd}$ & $61.1 \pm 25.3 b c$ & 98.6 \\
\hline & M2 & Hypocotyls & $54.2 \pm 30.0 \mathrm{bc}$ & $45.8 \pm 30.0 \mathrm{~cd}$ & 100 \\
\hline & M2 & Roots & $12.5 \pm 19.8 \mathrm{e}$ & $83.3 \pm 25 \mathrm{a}$ & 95.8 \\
\hline
\end{tabular}

${ }^{2}$ Data represent the averages of nine petri dishes per treatment. Each petri dish contained eight explants. ${ }^{y}$ The M1 medium contained Murashige and Skoog (MS) mineral salts plus vitamins, $0.89 \mu$ M NAA, 8.07 $\mu \mathrm{M}$ CPPU, $2.5 \%\left(\mathrm{w} \cdot \mathrm{v}^{-1}\right)$ sucrose, and $0.7 \%\left(\mathrm{w} \cdot \mathrm{v}^{-1}\right)$ agar $(\mathrm{pH} 5.7)$. M2 medium contained MS mineral salts plus vitamins, $3.12 \mu \mathrm{M}$ of NAA with $8.07 \mu \mathrm{M}$ CPPU, $2.5 \%\left(\mathrm{w} \cdot \mathrm{v}^{-1}\right)$ sucrose, and $0.7 \%\left(\mathrm{w} \cdot \mathrm{v}^{-1}\right)$ agar $(\mathrm{pH} 5.7)$. Cultured under a condition of 16-h light and 8-h dark cycle at $25{ }^{\circ} \mathrm{C}$ with a light intensity of 50 $\mu \mathrm{mol} \cdot \mathrm{m}^{-2} \cdot \mathrm{s}^{-1}$.

${ }^{x}$ Mean separation within columns was by least significant means difference Student's $t$ test $(P \leq 0.05)$.

Table 3. The number of induced shoots per explant from A. canadensis and A. racemosus with three types of explants on two induction media. ${ }^{z}$

\begin{tabular}{lclc}
\hline Species & Medium $^{\mathrm{y}}$ & Explants & Shoots per explant \\
\hline A. canadensis & M1 & Cotyledons & $10.0 \pm 1.3 \mathrm{a}^{\mathrm{x}}$ \\
& M1 & Hypocotyls & $4.9 \pm 0.5 \mathrm{~b}$ \\
M1 & Roots & $4.9 \pm 0.8 \mathrm{~b}$ \\
M2 & Cotyledons & $9.0 \pm 2.9 \mathrm{a}$ \\
A. racemosus & Hypocotyls & $4.1 \pm 1.8 \mathrm{bc}$ \\
& M2 & Roots & $1.9 \pm 0.8 \mathrm{def}$ \\
M1 & Cotyledons & $1.6 \pm 1.8 \mathrm{def}$ \\
M1 & Hypocotyls & $3.0 \pm 1.9 \mathrm{~cd}$ \\
M1 & Roots & $0.7 \pm 0.8 \mathrm{f}$ \\
M2 & Cotyledons & $1.0 \pm 0.8 \mathrm{ef}$ \\
M2 & Hypocotyls & $2.3 \pm 1.9 \mathrm{de}$ \\
M2 & Roots & $0.6 \pm 0.7 \mathrm{f}$ \\
\hline
\end{tabular}

${ }^{2}$ Data represent the averages of nine petri dishes per treatment. Each petri dish contained eight explants. ${ }^{\mathrm{y}}$ The M1 medium contained Murashige and Skoog (MS) mineral salts plus vitamins, $0.89 \mu \mathrm{M}$ NAA, 8.07 $\mu_{\mathrm{M}}$ CPPU, $2.5 \%\left(\mathrm{w} \cdot \mathrm{v}^{-1}\right)$ sucrose, and $0.7 \%\left(\mathrm{w} \cdot \mathrm{v}^{-1}\right)$ agar $(\mathrm{pH} 5.7)$. M2 medium contained MS mineral salts plus vitamins, $3.12 \mu \mathrm{M}$ of NAA with $8.07 \mu \mathrm{M}$ CPPU, $2.5 \%\left(\mathrm{w} \cdot \mathrm{v}^{-1}\right)$ sucrose, and $0.7 \%\left(\mathrm{w} \cdot \mathrm{v}^{-1}\right)$ agar $(\mathrm{pH} 5.7)$. Cultured under a condition of 16-h light and 8-h dark cycle at $25{ }^{\circ} \mathrm{C}$ with a light intensity of 50 $\mu \mathrm{mol} \cdot \mathrm{m}^{-2} \cdot \mathrm{s}^{-1}$.

${ }^{x}$ Mean separation within columns was by least significant means difference Student's $t$ test $(P \leq 0.05)$.

rooted. Rooting rates of $A$. canadensis and $A$. racemosus shoots were $43 \%$ and $19 \%$, respectively.

\section{Discussion}

Our culture results demonstrate that the plant regeneration system was successfully established for both the Se-hyperaccumulator $A$. racemosus and the nonaccumulator $A$. canadensis with $\mathrm{M} 1$ and M2 media. $A$. canadensis is better than A. racemosus for shoot induction under the current conditions. However, because the calli derived from $A$. racemosus tissue culture could develop into shoots on rooting medium, the system we developed is sufficient for plant regeneration from both species.

Different genotypes having different culture responses under the same induction conditions have been documented before, which may result from different endogenous hormone levels in different genotypes (Kasha et al., 1990). This is also true for different tissues used for shoot induction. Among all of the different types of explants used in our certain types of growth regulators might well be the result of species specificity. The better effect of CPPU on the callus/shoot induction may result from its strong cytokinin function. Compared with BA, CPPU is a strong cytokinin for cell division and callus proliferation (Takahashi et al., 1978). The other reason is the CPPU is more stable and has a different metabolism compared with the natural cytokine, BA (Mok and Mok, 2001). The effect of CPPU on increasing cell division and proliferation is through upregulating the expression of the $C y c D 3$ gene, which encodes the CycD cyclins involving regulating the G1 phase during cell cycle (Li et al., 2003).

Calli derived from all three types of $A$. racemosus explants and $A$. canadensis cotyledons were green, whereas some calli from A. canadensis hypocotyls and roots appeared to be rust-colored, which was somehow different from the report of Ziebur and Shrift (1971). In their hypocotyl culture, calli from A. canadensis were green, whereas those from $A$. racemosus were rust-colored, beige, or pale green. This difference may be caused by the different induction medium used, although the actual cause of the rust-colored calli is not clear. The exact cause of rustcolored calli in A. canadensis needs to be further investigated. Interestingly, this rust color was also observed in our cell suspension culture. Both cell suspension lines derived from $A$. canadensis cotyledon and root calli showed a pale rust color and grew relatively faster than those from $A$. racemosus, which were white to yellow (our unpublished data).

In conclusion, this is the first report of plant regeneration from both the Se-hyperaccumulator $A$. racemosus and the nonaccumulator $A$. canadensis in three different types of explants. Although the Se-hyperaccumulating characteristic has been recognized for many decades in some Astragalus species, only one gene, encoding selenocysteine methyltransferase, has been isolated and confirmed to be related to the Se accumulation in A. bisulcatus leaves. These established plant regeneration and callus induction systems for both $A$. racemosus and $A$. canadensis will allow us to develop a transformation system and cell suspension culture lines for study of Se accumulation. The cell suspension culture lines could also be used for $\mathrm{Se}$ treatment to induce Se-related differentially expressed genes, and a future Astragalus transformation system will facilitate the isolation and characterization of more Se-accumulating genes.

\section{Literature Cited}

bination. In our study, NAA combined with cytokine-like CPPU, a synthetic phenylurea derivative (Takahashi et al., 1978), proved to be effective for $A$. racemosus and $A$. canadensis tissue culture, leading to the production of either calli or calli with shoots in most of the placed explants. Other growth regulator combinations tested in our preliminary work indicated that CPPU was better than BA and that NAA was better than 2,4-D for our culture purposes. These preferences toward
Berken, A., M.M. Mulholland, D.L. LeDuc, and N. Terry. 2002. Genetic engineering of plants to enhance selenium phytoremediation. Crit. Rev. Plant Sci. 21:567-582.

Birringer, M., S. Pilawa, and L. Flohe. 2002. Trends in selenium biochemistry. Nat. Prod. Rep. 19:693-718.

Cunningham, S.D., J.R. Shann, D.E. Crowley, and T.A. Anderson. 1997. Phytoremediation of contaminated water and soil. In: Kruger, E.L., 
T.A. Anderson, and J.R. Coats (eds.). Phytoremediation of soil and water contaminants, ACS Symposium Series No. 664. American Chemical Society, Washington, DC.

Davis, A.M. 1972. Selenium accumulation in Astragalus species. Agron. J. 64:751-754.

Finley, J.W. 2005. Proposed criteria for assessing the efficacy of cancer reduction by plant foods enriched in carotenoids, glucosinolates, polyphenols and selenocompounds. Ann. Bot. (Lond.) 95:1075-1096.

Fiore, S., F.D. Pasquale, F. Carimi, and S. Maurizio. 2002. Effect of 2,4-D and 4-CPPU on somatic embryogenesis from stigma and style transverse thin cell layer of citrus. Plant Cell Tissue Organ Cult. 68:57-63.

Kasha, K.J., A. Ziauddin, and E. Simion. 1990. Barley and wheat microspore culture. Abstr. 7th Int. Congress on Plant Cell Tissue Culture, Amsterdam. p. 187.

Khanna, H.K. and S.K. Raina. 1998. Genotype $\times$ media interaction effects on callus-mediated green plant regeneration efficiency in three indica rice cultivars. Plant Cell Tissue Organ Cult. 52:145-153.

Komai, F., I. Okuse, and T. Harada. 1996. Somatic embryogenesis and plant regeneration in culture of root segments of spinach (Spinacia oleracea L). Plant Sci. 113:203-208.

Li, Y., J.Q. Yu, Q.J. Ye, Z.J. Zhu, and Z.J. Guo. 2003. Expression of CycD3 is transiently increased by pollination and $\mathrm{N}$-(2-chloro-4pyridyl)- $N^{\prime}$-phenylurea in ovaries of Lagenaria leucantha. J. Expt. Bot. 54:1245-1251.
Millan-Mendoza, B.M. 1998. Regeneration of Rubus in vitro using forchlorfenuron (CPPU). Rev. Fac. Agron. (LUZ) 15:242-248.

Mok, D.W.S. and M.C. Mok. 2001. Cytokinin metabolism and action. Annu. Rev. Plant Physiol. Plant Mol. Biol. 52:89-118.

Murashige, T. and F. Skoog. 1962. A revised medium for rapid growth and bioassays with tobacco tissue cultures. Physiol. Plant. 15:473497.

Murthy, B.N.S. and P.K. Saxena. 1994. Somatic embryogenesis in peanut (Arachis hypogaea L.): Stimulation of direct differentiation of somatic embryos by forchlorfenuron (CPPU). Plant Cell Rep. 14:145-150.

Murthy, B.N.S., R.P. Singh, and P.K. Saxena. 1996. Induction of high-frequency somatic embryogenesis in geranium (Pelargonium $\times$ hortorum Bailey cv. Ringo Rose) cotyledonary cultures. Plant Cell Rep. 15:423-426.

Nakajima, I., S. Kobayashi, and Y. Nakamura. 2000. Embryogenic callus induction and plant regeneration from unfertilized ovule of 'Kyoho' grape. J. Jpn. Soc. Hort. Sci. 69:186-188.

Neuhierl, B., M. Thanbichler, F. Lottspeich, and A. Bock. 1999. A family of S-methylmethioninedependent thiol/selenol methyltransferases. Role in selenium tolerance and evolutionary relation. J. Biol. Chem. 274:5407-5414.

Okubo, H., K. Wada, and S. Uemoto. 1991. In vitro morphogenetic response and distribution of endogenous plant hormones in hypocotyl segments of snapdragon (Antirrhinum majus L.). Plant Cell Rep. 10:501-504.
Schwarz, K. and C.M. Foltz. 1957. Selenium as an integral part of factor 3 against dietary necrotic liver degeneration. J. Amer. Chem. Soc. 70:3292-3293.

Sors, T.G., D.R. Ellis, and D.E. Salt. 2005. Selenium uptake, translocation, assimilation and metabolicfate in plants. Photosynth. Res. 86:373-389.

Takahashi, S., K. Shudo, T. Okamoto, K. Yamada, and Y. Isogai. 1978. Cytokinin activity of $N$-phenyl- $N^{\prime}$-(4-pyridyl)urea derivatives. Phytochemistry 17:1201-1207.

Trelease, S.F. and H.M. Trelease. 1939. Physiological differentiation in Austragalus with reference to selenium. Amer. J. Bot. 26:530 535.

Tsuro, M., M. Koda, and M. Inoue. 1999. Comparative effect of different type of cytokinin for shoot formation and plant regeneration in leafderived callus of lavender (Lavandula vera DC). Sci. Hort. 81:331-336.

Xie, J.H., M.W. Gao, Q.H. Cai, X.Y. Cheng, Y.W. Shen, and Z.Q. Liang. 1995. Improved isolated microspore culture efficiency by medium with maltose and optimal growth regulator combination in japonica rice. Plant Cell Tissue Organ Cult. 42:245-250

Zhang, Q., J. Chen, and R.J. Henny. 2005. Direct somatic embryogenesis and plant regeneration from leaf, petiole and stem explants of Golden Pothos. Plant Cell Rep. 23:587-595.

Ziebur, N.K. and A. Shrift. 1971. Response to selenium by callus cultures derived from Astragalus species. Plant Physiol. 47:545-550. 